\title{
Potentiometric Determination of Cyanamide Using a Silver Sulfide Membrane-Type Ion-Selective Electrode
}

\author{
Tetsutaro Yoshinaga, Masaaki Koga and Kentaro Kawano \\ Department of Chemistry, Faculty of Engineering, Kyushu Institute of Technology, \\ Sensuicho, Tobata, Kitakyushu 804, Japan
}

\begin{abstract}
Potentiometric titration was successfully applied for the determination of cyanamide (Cy) using a silver sulfide membranetype ion-selective electrode. In a Cy concentration range of 0.02 to $0.08 \mathrm{M}$ in a $1 \mathrm{M} \mathrm{NaOH}$ solution, $98.9 \%$ of the cyanamide was recovered $\left(\mathrm{RSD}=0.08 \%, n=10\right.$ ). The detection limit of $\mathrm{Cy}$ by the present method is around $6 \times 10^{-4} \mathrm{M}$ with a positive error of $c a .1 \%$, an RSD of $0.2 \%$, and an $n$ of 4 . The coexistence of cyanoguanidine, urea, sulfide and chloride at a molar ratio of $0.3: 1.5: 0.3: 1.0$ to 1 part of $\mathrm{Cy}$ did not affect the determination of $\mathrm{Cy}$.
\end{abstract}

Keywords Potentiometric titration, cyanamide, silver sulfide membrane, ion-selective electrode.

Calcium cyanamide is known to be a useful nitrogen fertilizer; cyanamide $\left(\mathrm{H}_{2} \mathrm{~N}-\mathrm{CN}\right.$ : $\mathrm{Cy}$ ), a compound derived from calcium cyanamide, has been in widespread use as a chemical intermediate, such as cyanoguanidine, other guanidine derivatives and thiourea as well as being used in textile fire-proofing, defoliants and wood-pulp processing. Traditionally, $\mathrm{Cy}$ has been determined by precipitation with ammoniacal silver nitrate followed by the titration of silver in the precipitate by the Volhard method. ${ }^{1-3}$ However, this method is time-consuming, applicable only to macro amounts of $\mathrm{Cy}$ and requires elaborate operations. On the other hand, several instrumental methods have been developed, such as spectrophotometry $^{4}$, the reaction rate method ${ }^{3}$, potentiometry $^{5-7}$, and HPLC ${ }^{8}$, for the determination of Cy. Buyske and Downing ${ }^{4}$ developed a spectrophotometric method for $\mathrm{Cy}$ based on the formation of a purple complex $\left(\lambda_{\max }: 530 \mathrm{~nm}\right)$ with sodium pentacyanoammineferrate(II) $\left(\mathrm{Na}_{3}\left[\mathrm{Fe}(\mathrm{CN})_{5} \mathrm{NH}_{3}\right]\right.$; SPF) in a carbonate buffer of pH 10.5. Their method had a lower limit of sensitivity ( $1 \mu \mathrm{g}$ in $1.3 \mathrm{ml}$ or $0.77 \mathrm{ppm}$ ) and exhibited a linear response from 1 to $52.5 \mu \mathrm{g}$ (reproducibility, $c a$. 5\%). Nieman et $a .^{3}$ developed an initial-rate method for trace amounts of $\mathrm{Cy}$. The initial rate was measured as the rate of absorbance increase due to the formation of an SPF-Cy complex. Their calibration curve was linear for $1 \times 10^{-7}-3 \times 10^{-7} \mathrm{M}$ with a detection limit of $13 \mathrm{ppb}$ and a precision of $3.5 \%$. A sensitive method for the determination of $\mathrm{Cy}$ in plasma was developed by Prunonosa et $a l .{ }^{8} \quad$ Their procedure involved extraction, derivatization and a posterio analysis by HPLC with a fluorometric detector. The linearity ranged from 5 to $500 \mathrm{ng} / \mathrm{ml}$ and the lower detection limit of $\mathrm{Cy}$ in a plasma was $4 \mathrm{ng} / \mathrm{ml}$ with a precision of $3-8.9 \%$. These results illustrate that instrumental methods generally do not give good reproducibility. Sato et al. studied the analytical meth- ods for determining cyanide and $\mathrm{Cy}$ for use in the preparation of cyanide compounds from lime nitrogen. They proposed a potentiometric method to determine cyanide ions and $\mathrm{Cy}$ in a mixture of these compounds using a silver electrode; those species were determined by repetitive titrations under different conditions. ${ }^{5}$ Their method, however, is not appropriate for determining $\mathrm{Cy}$ under an alkaline condition. The influence of the ammoniacal alkaline condition was especially strong. ${ }^{6}$ In recent years, investigations of ion-selective electrodes (ISE) have been intensively carried out, and many sensitive and stable electrodes have been developed. ISE can now be used to determine even organic compounds indirectly. For example, Pungor et al. ${ }^{9}$ determined thiourea in $1 \mathrm{M}$ and $0.1 \mathrm{M} \mathrm{NaOH}$ solutions using a silver sulfide electrode as an indicator electrode with a lower detection limit of $10^{-3} \mathrm{M}$. In the present work, considering the situations of the official analytical method of $\mathrm{Cy}^{1}$, as mentioned above, the authors have established an accurate and precise potentiometric method for determining $\mathrm{Cy}$ in (1M) $\mathrm{NaOH}$ solutions in the presence of several componds using an ion-selective (silver sulfide membrane type) electrode with a detection limit of $6 \times 10^{-4} \mathrm{M}$ (or $6 \mu \mathrm{g}$ ) $\mathrm{Cy}$.

\section{Experimental}

\section{Reagents}

Standard silver nitrate solution: an analytical-grade reagent of silver nitrate from Wako Pure Chemicals was dissolved in distilled water to obtain a $0.10 \mathrm{M}$ standard stock solution.

Cyanamide (Cy): crude crystal cyanamide prepared from commercially obtained $\mathrm{LN}$ was purified by repeated extraction with dried diethylether and crystallization 
by solvent evaporation. Analytical value: (1) official method $^{1}=99.00 \%$, (2) the calculated value from Kjeldahl nitrogen $=99.04 \%$. Based on these values, the purity of Cy is considered to be $99.0 \%$ in what follows.

Crystalline $\mathrm{Cy}$ is hygroscopic; an excess amount of a sample was weighed using a weighing bottle and dried on $\mathrm{P}_{4} \mathrm{O}_{10}$ until a constant weight was obtained in a desiccator. Then, a prescribed quantity of dried $\mathrm{Cy}$ was weighed immediately and dissolved into a $1 \mathrm{M} \mathrm{NaOH}$ solution to a given volume of a volumetric flask (Cy standard stock solution).

Dicyanodiamide ( $=$ cyanoguanidine, $\mathrm{CG}$ ): An reagentgrade crystal obtained from Tokyo Kasei Co. Ltd. was recrystallized twice from water (m.p. $209^{\circ} \mathrm{C}$ (reference: $\left.209^{\circ} \mathrm{C}^{10}\right)$ ). The purity from Kjeldahl nitrogen $=100.0 \%$.

Urea and sodium sulfide used were of reagent grade obtained from Wako Pure Chemicals. Sodium chloride used was a primary standard from Wako Pure Chemicals. For urea and sodium sulfide stock solutions, standardization was performed before use.

\section{Apparatus}

A potentiometer (Kyoto Electronic Industry; AT-06 type) was used to determine the cyanamide concentration. A silver-sulfide type ion-selective electrode (Toyo Scientific Industry) was used to detect silver ions. A sleeve-type electrode (Horiba Seisakusho No. 2630; $\mathrm{Ag} / \mathrm{AgCl}$ ), in which a $3.3 \mathrm{M} \mathrm{KCl}-\mathrm{AgCl}$ (sat.) solution is used as an inner solution, was used as a reference electrode.

\section{Potentiometric titration}

The silver sulfide electrode was immersed in a $\mathrm{Cy}$ dissolved solution (in $1 \mathrm{M} \mathrm{NaOH}$ ), and connected to a reference electrode through a salt bridge (agar gel- $\mathrm{KNO}_{3}$ aq.). A small amount of $\mathrm{AgNO}_{3}$ std. solution was dropped intermittently through a micro-buret, and the potentials were measured at equilibrium.

\section{Analytical reaction and principle}

Cy reacts with silver ions, producing an insoluble yellow-silver cyanamide salt as follows (Eq. (1)):

$$
\mathrm{NH}_{2}-\mathrm{CN}+2 \mathrm{Ag}^{+} \rightleftharpoons \mathrm{Ag}_{2} \mathrm{~N}-\mathrm{CN}+2 \mathrm{H}^{+} .
$$

Since the silver cyanamide that is formed can be dissolved in a weak acid, this reaction is reversible. It is thus necessary to neutralize the hydrogen ions produced to make the reaction proceed quantitatively.

The addition of a base to an amount of more than twice that of $\mathrm{Cy}$ (molar ratio) is required before titration. In an actual experiment, dark-brown precipitates (ppt.) appeared during the first titration; then, the color of the ppt. rapidly changed to yellowish. This means that silver ions initially reacted with hydroxide ions which existed in great excess to give silver hydroxide ( $\mathrm{AgOH})$, followed by silver oxide $\left(\mathrm{Ag}_{2} \mathrm{O}\right)$. Immediately after, the equilibrium rapidly moved to the formation of silver cyanamide, which has a smaller solubility product.

\section{The Nernst equation for silver ions is}

$$
E=E_{0}+(R T / F) \ln \left[\mathrm{Ag}^{+}\right] .
$$

When silver ions $\left(\mathrm{Ag}^{+}\right)$were added to the sample solution under an alkaline condition, most of them were rapidly consumed and equilibrium was reached according to Eq. (1); also, a constant potential was attained due to a very small amount of residual $\mathrm{Ag}^{+}$ions. The potential was nearly constant during titration, because of the constancy of the residual $\mathrm{Ag}^{+}$concentration. After complete consumption of $\mathrm{Cy}$, the $\mathrm{Ag}^{+}$ions added to the solution remain unreacted, and the potential showed a rapid increase. This break point (end point) corresponds approximately to the equivalence point.

\section{Results and Discussion}

\section{Titration under alkaline conditions}

Ten milliliters of a Cy solution $\left(6.0 \times 10^{-2} \mathrm{M}\right.$ in $1 \mathrm{M}$ $\mathrm{NaOH}$ ) was titrated with a $0.10 \mathrm{M} \mathrm{AgNO}_{3}$ standard solution (std. Ag solution); the potentiometric titration curves are shown in Fig. 1. The broken curve exhibits a rapid rise in potential during the initial stage $(P)$, followed by a plateau until the next (second) rapid rise occurs at around the equivalence point $\left(v_{1}=12.0 \mathrm{ml}\right)$ of $\mathrm{Cy}$. To clarify the reason for the initial potential rise, microtitration was carefully carried out by limiting the titration to the initial region; the results are shown in Fig. 2. It can be seen that the rapid potential rise took place at a titration volume of $0.03 \mathrm{ml}\left(v_{\mathrm{p}}\right)$, where the formation of a black ppt. was observed. This black ppt. was considered to be sulfide, because a small amount of sulfide is usually contained in Cy. To confirm this, the

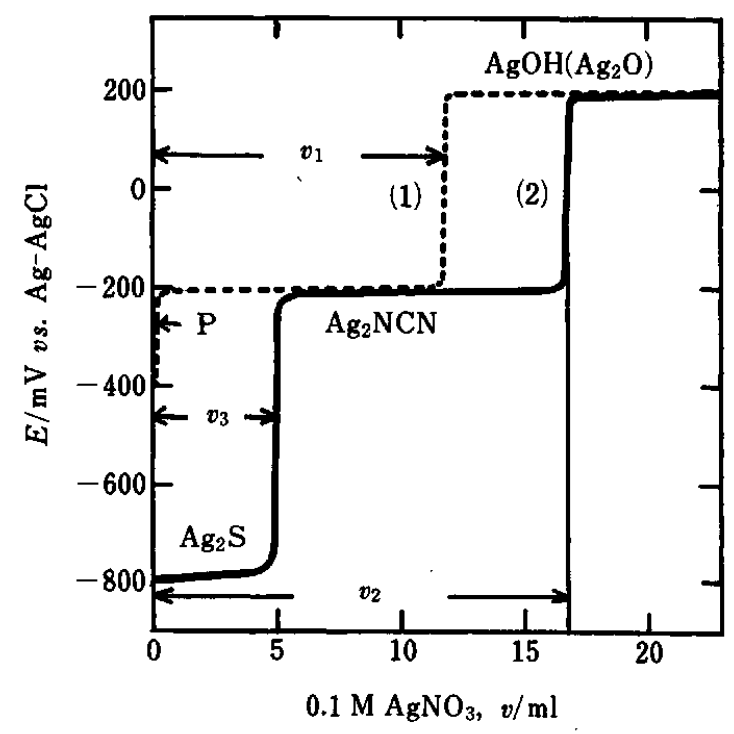

Fig. 1 Potentiometric titration curves of cyanamide in a $1 \mathrm{M}$ $\mathrm{NaOH}$ solution. (1) cyanamide $(0.6 \mathrm{mmol}) ;(2)$ cyanamide $(0.6 \mathrm{mmol})+$ sodium sulfide $(0.25 \mathrm{mmol})$. 


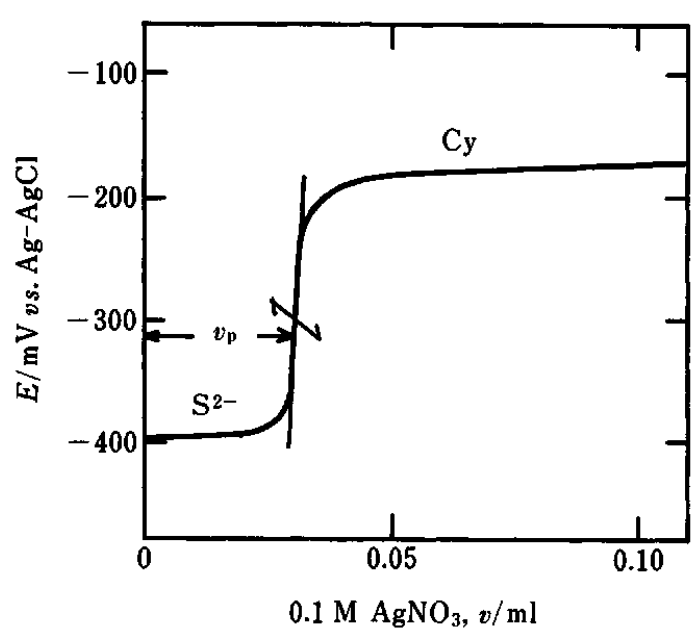

Fig. 2 Micro-titration curve of cyanamide and impurity $\left(\mathrm{S}^{2-}\right)$ in a $1 \mathrm{M} \mathrm{NaOH}$ solution. Amount of cyanamide: 0.6 mmol.

following experiment was carried out. A known amount of sodium sulfide was added to a $\mathrm{Cy}$ alkaline solution and titrated under the same condition as mentioned above, obtaining the solid curve in Fig. 1(2). As expected, the potential was nearly constant, showing no potential jump until the titration volume reached the volume corresponding to the quantity of sulfide added. A rapid potential jump appeared thereafter. Further titration gave the same length of plateau as that in Fig. 1(1), followed by a second potential jump. The distance between the two potential jump points in the abscissa remained the same upon titration with and without sodium sulfide. A correction value of $0.03 \mathrm{ml}$ (corresponding roughly to 1 drop), due to sulfide, may be negligibly small, but requires a correction for an accurate determination. Since the potential jumps due to sulfide and $\mathrm{Cy}$ are clearly separated from each other, the preaddition of sulfide should give more accurate analytical results for the determination of $\mathrm{Cy}$. Besides, this preaddition method should yield the exact value of the sulfide quantity in the sample.

It must be noted here that the value of the intial potential $(c a .-400 \mathrm{mV})$ at a sufficiently low concentration of sulfide $\left(10^{-4} \mathrm{M}\right)$ was quite different from the potential $(c a .-800 \mathrm{mV})$ at a relatively high concentration of sulfide $\left(10^{-2}-10^{-1} \mathrm{M}\right)$, which was intentionally added. This apparent discrepancy may be rationalized as follows. If the Nernst equation is to hold for sulfide ions, the use of the solubility product in water gives the equation $E\left(\mathrm{~S}^{2-} ; \mathrm{mV}\right.$ vs. $\left.\mathrm{Ag} / \mathrm{AgCl}\right)=-900-29 \log \left[\mathrm{S}^{2-}\right]$. The present experiment, however, was carried out in a $1 \mathrm{M} \mathrm{NaOH}$ solution, and an appropriate Nernst equation under these conditions would be

$$
\begin{aligned}
& E\left(\mathrm{~S}^{2-} \text { in } 1 \mathrm{M} \mathrm{NaOH} ; \mathrm{mV} \text { vs. } \mathrm{Ag} / \mathrm{AgCl}\right) \\
& \quad=-830-29 \log \left[\mathrm{S}^{2-}\right] \quad\left(10^{-4} \mathrm{M}<\left[\mathrm{S}^{2-}\right]<10^{0} \mathrm{M}\right),
\end{aligned}
$$

and at concentrations of $10^{-4} \mathrm{M}$ or lower, the potential should show a rapid increase. A schematic figure illustrating this behavior is depicted in Fig. 3, where the broken curve shows an imaginary potential curve obeying the Nernst equation.

By varying the Cy concentration from $8.0 \times 10^{-2}$ to $2.0 \times 10^{-2} \mathrm{M}$, Cy was potentiometrically determined under the same conditions as stated above. A clear potential jump was obtained at each concentration; the results are summarized in Table 1 . It can be seen that the percent recovery was nearly constant (98.9\%), allowing for experimental error. The correlation between the analytical and calculated concentrations was nearly perfect $(r=1.0000)$.

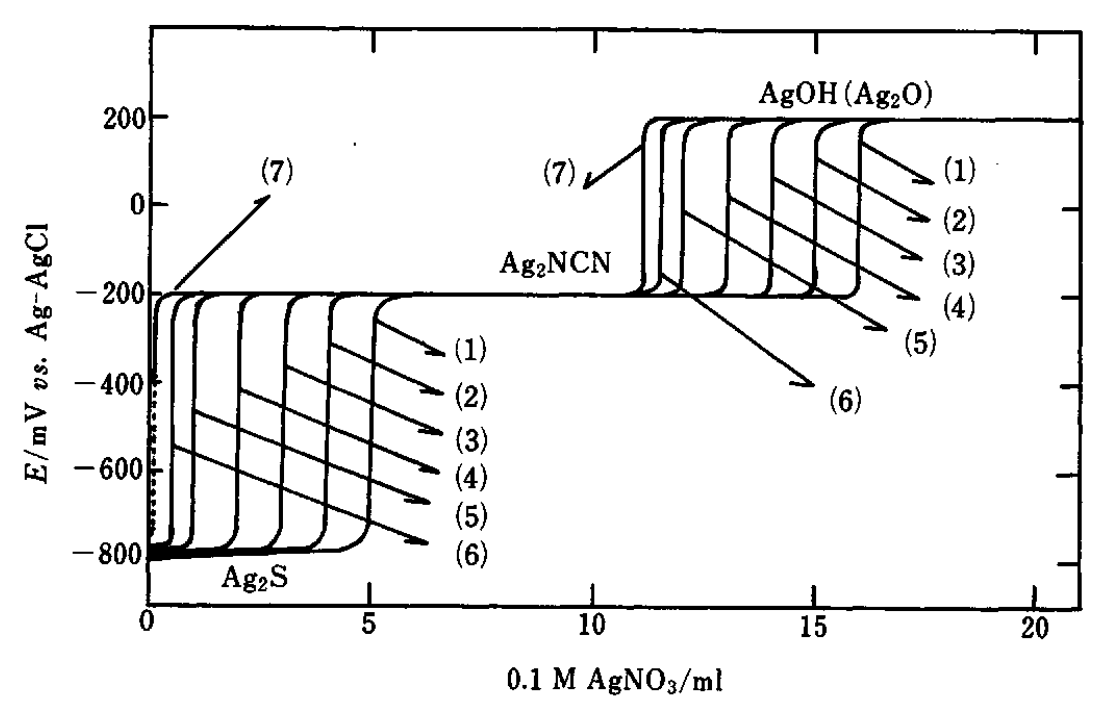

Fig. 3 Schematic titration curves for the interpretation of the shift of initial potentials as a function of the sulfide ion concentrations. [ $\left[\mathrm{S}^{2-}\right]$ : (1), $10 \times 10^{-3} \mathrm{M}$; (2), $8 \times 10^{-3} \mathrm{M} ;(3), 6 \times 10^{-3} \mathrm{M} ;(4), 4 \times 10^{-3} \mathrm{M} ;(5), 2 \times 10^{-3} \mathrm{M}$; (6), $1 \times 10^{-3} \mathrm{M} ;(7), 1 \times 10^{-4} \mathrm{M}$. 
Table 1 Determination of cyanamide in $1 \mathrm{M} \mathrm{NaOH}$ by potentiometric titration using a $0.1 \mathrm{M} \mathrm{AgNO}_{3}$ solution as the titrant

\begin{tabular}{cccr}
\hline \multirow{2}{*}{$\begin{array}{c}\text { Concentration } \\
\text { of cyanamide }\end{array}$} & \multicolumn{2}{c}{ Titrant $\left(\mathrm{AgNO}_{3}\right)$ added $/ \mathrm{ml}$} & \multirow{2}{*}{$\begin{array}{c}\text { Percent } \\
\text { recovery }\end{array}$} \\
\cline { 2 - 3 } & Calcd. & Found & \\
\hline $8.0 \times 10^{-2} \mathrm{M}$ & 15.84 & 15.64 & $98.7 \%$ \\
$6.0 \times 10^{-2} \mathrm{M}$ & 11.88 & 11.76 & $99.0 \%$ \\
$4.0 \times 10^{-2} \mathrm{M}$ & 7.92 & 7.84 & $99.0 \%$ \\
$2.0 \times 10^{-2} \mathrm{M}$ & 3.96 & 3.91 & $98.8 \%$ \\
& & & av. $98.9 \%$ \\
\hline
\end{tabular}

a. Sample volume: $10.0 \mathrm{ml}$.

As stated above, Sato et al. used a potentiometric method to determine Cy (especially in LN) with a silver electrode. ${ }^{4,5}$ Under their conditions, however, the existence of excess alkali led to a large positive error, while under our conditions, even in $1 \mathrm{M} \mathrm{NaOH}$, high accuracy and precision were attained.

\section{Detection limit of $C y$}

When the Cy concentration in a $1 \mathrm{M} \mathrm{NaOH}$ solution was decreased from $8.0 \times 10^{-3}$ to $2.0 \times 10^{-3} \mathrm{M}$ and $10 \mathrm{ml}$ of the $\mathrm{Cy}$ solution was titrated with a $10^{-2} \mathrm{M} \mathrm{AgNO}_{3}$ std. solution, the accuracy and precision were approximately the same as those for higher $\mathrm{Cy}$ concentrations, though the electrode response was slow. For example, it was 5 to $10 \mathrm{~s}$ for titration with a $0.1 \mathrm{M} \mathrm{AgNO}_{3}$ std. solution, while it was around $1 \mathrm{~min}$ with a $10^{-2} \mathrm{M} \mathrm{AgNO}_{3}$ std. solution. By further lowering of the $\mathrm{Cy}$ concentration to $8.0 \times 10^{-4}$ to $2.0 \times 10^{-4} \mathrm{M}$, the response time became $3-$ $4 \mathrm{~min}$, and, as expected from the Nernst equation, the extent of the potential jump became small; hence, the end point became somewhat obscure. Thus, the relative positive error at a Cy concentration of $4 \times 10^{-4} \mathrm{M}$ amounted to $c a$. 5\%. From the results given in Table 2, we conclude that the present potentiometric determination of $\mathrm{Cy}$ (in $1 \mathrm{M} \mathrm{NaOH}$ ) accompanies a detection limit of $6 \times 10^{-4} \mathrm{M}$ (relative error $=1 \%$; reproducibility $(\mathrm{RSD})=$ $0.2 \%, n=4)$.

The time required for the titration method changes with the $\mathrm{Cy}$ concentration. It was around $20 \mathrm{~min}$ at $\mathrm{Cy}$ concentrations of $2.0 \times 10^{-2}$ to $8.0 \times 10^{-2} \mathrm{M}$, and around $100 \mathrm{~min}$ at $6.0 \times 10^{-4} \mathrm{M}$ (lower detection limit). From a practical point of view, the $\mathrm{Cy}$ concentration of $1 \times$ $10^{-3} \mathrm{M}$, requiring $c a .30 \mathrm{~min}$, may be a practical detection limit.

\section{Influence of $\mathrm{NaOH}$ concentration}

According to Eq. (1), the molar amount of the base quantity required to neutrarize the acid produced by the $\mathrm{Cy}-\mathrm{Ag}^{+}$reaction is at least twice that of $\mathrm{Cy}$. In the present work, the maximum concentration of $\mathrm{Cy}$ was $0.08 \mathrm{M}$, i.e., the concentration of $\mathrm{NaOH}$ needed was at least $0.16 \mathrm{M}$. In view of this, we examined the effects of the $\mathrm{NaOH}$ concenration in the range of 0.2 to $2.0 \mathrm{M}$. The electromotive force (emf) was occasionally unstable at $0.2 \mathrm{M} \mathrm{NaOH}$, but was stable in the 0.5 to $2.0 \mathrm{M}$ range.
Table 2 Determination limit of the present method for cyanamide in $1 \mathrm{M} \mathrm{NaOH}$

\begin{tabular}{ccc}
\hline $\begin{array}{c}\text { Concentration } \\
\text { of cyanamide }\end{array}$ & $100 \times\left(\Delta V^{\mathrm{a}} / V_{\text {theo }}\right)$ & $\begin{array}{c}\text { Standard } \mathrm{AgNO}_{3} \\
\text { concentration }\end{array}$ \\
\hline $8.0 \times 10^{-3} \mathrm{M}$ & $0.0 \%$ & $10^{-2} \mathrm{M}$ \\
$2.0 \times 10^{-3} \mathrm{M}$ & $0.0 \%$ & $10^{-2} \mathrm{M}$ \\
$8.0 \times 10^{-4} \mathrm{M}$ & $0.0 \%$ & $10^{-3} \mathrm{M}$ \\
$6.0 \times 10^{-4} \mathrm{M}$ & $0.9 \%$ & $10^{-3} \mathrm{M}$ \\
$4.0 \times 10^{-4} \mathrm{M}$ & $4.8 \%$ & $10^{-3} \mathrm{M}$ \\
$2.0 \times 10^{-4} \mathrm{M}$ & $8.2 \%$ & $10^{-3} \mathrm{M}$ \\
\hline
\end{tabular}

a. Difference of titrant volume added $\left(V_{\text {av }}\right)$ at the end point and theoretical volume ( $\left.V_{\text {theo }}\right)$ at the equivalent point $\Delta V=$ $V_{\text {av }}-V_{\text {theo. }}$.

Finally, we chose $1 \mathrm{M}$ as being the most convenient $\mathrm{NaOH}$ concentration. The use of a relatively high concentration of $\mathrm{NaOH}$ also serves to adjust the ionic strength and to give a stable emf.

\section{Influence of coexisting substances}

The determination of $\mathrm{Cy}$ described above was carried out in Cy solutions with no coexisting compounds. In practical analyses, such as, in an analysis of lime nitrogen, we must often determine $\mathrm{Cy}$ with several coexisting substances. Although $\mathrm{Cy}$ is relatively stable in a weakly acidic solution having a $\mathrm{pH}$ of around 5 , in a weakly alkaline region ( $\mathrm{pH} 8-10(12)$ ), two $\mathrm{Cy}$ molecules dimerize to form $\mathrm{CG}$; in strongly acidic $(<\mathrm{pH} 2)$ or strongly alkaline $(>\mathrm{pH} 12)$ regions, $\mathrm{Cy}$ is hydrolized to form urea as follows: ${ }^{11}$

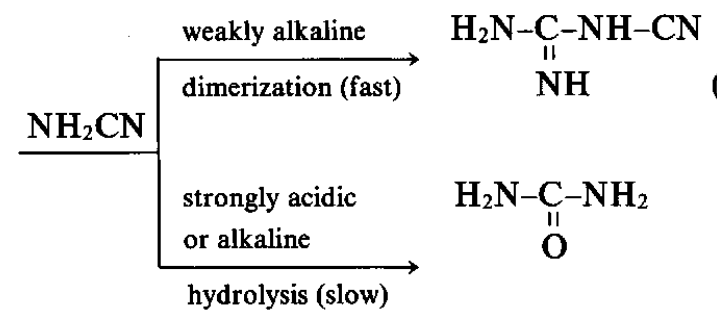

In additon to these compounds (CG and urea), which may be present in $\mathrm{LN}$, sulfide and chloride, which are usually contained in LN in small amounts, were chosen as the coexisting compounds in the potentiometric determinations of $\mathrm{Cy}$.

\section{Influence of $C G$}

CG is found in LN which has been stored for a long period. In the present measurement, the following CGto-Cy (CG: Cy) molar ratios were selected: (1) $0.1: 1.0$,(2) $0.3: 1.0$ and (3) $0.7: 1.0([\mathrm{Cy}]=0.02$ to $0.08 \mathrm{M}$ in $1 \mathrm{M}$ $\mathrm{NaOH}$ ). For cases (1) and (2), the potentiometric titration curves with potential jumps at the end points were the same as those without CG, while in the case of (3) the potential jump at the end point was less sharp, although the titration value obtained at the end point coincided with the former ones. CG is known to form a white insoluble silver salt when acidified with nitric acid. 
In the present measurement in a strongly alkaline solution, however, no silver salt ppt. formed and the Cy determination was not affected by CG.

\section{Influence of urea}

The urea-to-Cy (urea: $\mathrm{Cy}$ ) molar ratios were selected in a range from $3.0: 1.0$ to $1.0: 1.0$ under the same titration conditions as those for CG. The results were exactly the same as those obtained without urea in the determination of $\mathrm{Cy}(\mathrm{RSD}=0.12 \%, n=4)$.

\section{Influence of sulfide}

It was shown above that the existence of sulfide strongly affects the potentiometric titration profile. However, since the potential jump due to sulfide is very conspicuous and intense, it is easy to determine $\mathrm{Cy}$ by a differential titration method; i.e., the correct quantity of $\mathrm{Cy}$ is obtained by measuring the difference between the two jumps due to sulfide and $\mathrm{Cy}$ at the respective equivalence points. It was concluded that the coexistence of sulfide does not affect the determination of $\mathrm{Cy}$.

\section{Influence of chloride}

LN as a practical sample may contain a small amount of chloride as an impurity, and chloride ions in a $\mathrm{Cy}$ solution may react with silver ions to form silver chloride. Thus, chloride was added to the Cy solution and checked for interference with the determination of $\mathrm{Cy}$. The chloride-to-Cy $\left(\mathrm{Cl}^{-}: \mathrm{Cy}\right)$ molar ratios were chosen from $0.5: 1.0$ to $3.0: 1.0$, with the $\mathrm{Cy}$ concentration varying over a range of 0.02 to $0.08 \mathrm{M}$ in $1 \mathrm{M} \mathrm{NaOH}$. The results were as follows.

At a chloride concentration within the above-mentioned range, a yellow ppt. of silver cyanamide was always observed during titration with a $0.1 \mathrm{M} \mathrm{AgNO}_{3}$ std. solution. After complete consumption of $\mathrm{Cy}$, white precipitates were formed. In the potentiometric titration profile, although the potential jump at around the equivalence point of $\mathrm{Cy}$ and the subsequent plateau were found as usual, no subsequent potential jump corresponding to the chloride equivalent point was found, even when the titration was continued. The white color of the ppt. (silver chloride), however, changed to dark brown (silver oxide) upon continued titration beyond the equivalent point of chloride. The solubility products of silver sulfide, silver cyanamide, silver chloride and silver hydroxide are as follows: $K_{\mathrm{sp}}\left(\mathrm{Ag}_{2} \mathrm{~S}\right)=6 \times 10^{-50}$, $K_{\text {sp }}\left(\mathrm{Ag}_{2} \mathrm{~N}-\mathrm{CN}\right)=7.2 \times 10^{-11},{ }^{12} K_{\text {sp }}(\mathrm{AgCl})=(0.8-2.0) \times 10^{-10}$, $K_{\text {sp }}(\mathrm{AgOH})=2.6 \times 10^{-8}-4 \times 10^{-5}$. We cannot directly compare the solubilities of these salts in an alkaline solution using these data, because the latter were obtained in pure water. However, it is clear that silver cyanamide becomes more insoluble in an alkaline solution. On the other hand, silver chloride becomes more soluble, that is, $K_{\mathrm{sp}}\left(\mathrm{Ag}_{2} \mathrm{~N}-\mathrm{CN}\right)$ is far smaller than $K_{\text {sp }}(\mathrm{AgCl})$ in an alkaline solution. It is concluded that the coexistence of chloride in the molar ratio range stated above has no effect on the determination of $\mathrm{Cy}$.
Table 3 Effect of coexisting CG, urea, sulfide and chloride on the determination of cyanamide in $1 \mathrm{M} \mathrm{NaOH}$

\begin{tabular}{lccc}
\hline \multirow{2}{*}{$\begin{array}{l}\text { Coexisting } \\
\text { compound }\end{array}$} & $\begin{array}{c}\text { Molar ratio } \\
\text { to cyanamide }\end{array}$ & \multicolumn{2}{c}{ Percent recovery of cyanamide } \\
\cline { 3 - 4 } & & Singly added $^{\mathbf{a}}$ & All coexisting \\
\hline CG & 0.3 & $98.9 \%$ & \\
Urea & 1.5 & $98.8 \%$ & $(98.8 \%)$ \\
Sulfide & 0.3 & $98.9 \%$ & \\
Chloride & 1.0 & $98.7 \%$ & \\
\hline
\end{tabular}

a. Average of four determinations for $0.02-0.08 \mathrm{M} \mathrm{Cy}$ in $1 \mathrm{M} \mathrm{NaOH}$.

Table 4 Results of a lime nitrogen analysis

\begin{tabular}{|c|c|c|c|}
\hline \multirow{2}{*}{ Component } & \multicolumn{3}{|c|}{ Manufacturer names abbreviated } \\
\hline & $\mathbf{N}$ & $\mathrm{D}$ & $\mathbf{S}$ \\
\hline $\mathrm{CaCN}_{2}(\%)$ & 57.20 & 58.61 & 58.54 \\
\hline $\mathrm{CaS} \quad(\%)$ & 0.34 & 0.36 & 0.68 \\
\hline
\end{tabular}

Influence of the mixture of $C G$, urea, sulfide and chloride

The possibility of some negative effect by a mutual interaction of these four compounds was investigated by selecting the molar ratio $\mathrm{CG}$ : urea: sulfide: chloride:(Cy) as $0.3: 1.5: 0.3: 1.3:(1: 0)$. The titration conditions were the same as those used for the coexistence of a single compound. As a result, the potentiometric titration curves for these solutions were just the same as those for a $\mathrm{Cy}$ solution with no coexisting compounds, as summarized in Table 3.

\section{Influence of temperature}

The temperature effect on the determination of $\mathrm{Cy}$ was studied in a range from 10 to $30^{\circ} \mathrm{C}$; no effect was found on the determination of $\mathrm{Cy}$.

\section{Influence of light}

During the titration, because silver ions are the titrants and the ISE is made of silver sulfide, the effect of light on the determination of $\mathrm{Cy}$ was examined. It was found that although weak light did not affect the results, strong light (e.g., 104 lux) affected the electrode potential, and the potential was somewhat unstable (drifted). It is hence recommended to measure the potential under shaded conditions, though no influence is exerted by normal laboratory lighting.

\section{Analysis of lime nitrogen}

To assess the applicability of the present method, several commercial lime nitrogen (LN) products were analyzed; the results are given in Table 4 . In this experiment, several portions of LN sampled out from a lot were mixed and ground to a particle size of less than ca. $37 \mu \mathrm{m}$ ( 400 or higher mesh sieve). As can be seen in Table 4 , the present method yielded satisfactory analytical values. The products of three manufactures gave 
nearly the same contents for calcium cyanamide, and for calcium sulfide, except for that of one company. It was concluded from the results that the sulfide-to-cyanamide molar ratio in a product (ca. 7/1000 from N Co., Ltd.) was reduced to roughly one-seventh when it was purified (ca. 1/1000) (c.f. experimental section).

\section{References}

1. The National Institute of Agro-Environmental Science; "Official Methods of Analysis of Fertilizers", Ministry of Agriculture, Forestry and Fisheries, 1992.

2. M. Koshino ed., "Shokai Hiryou Bunsekihou (2nd ed)., (Detailed Explanations of Analytical Methods of Fertilizers (2nd ed.), in Japanese)", Yokendo, Tokyo, 1988.

3. T. A. Nieman, F. J. Holler and C. G. Enke, Anal. Chem., 48, 899 (1976).
4. D. A. Buyske and V. Downing, Anal. Chem., 32, 1798 (1960).

5. M. Sato, H. Sato and T. Fujisawa, Denki Kagaku, 22, 371 (1954).

6. M. Sato, H. Sato, T. Fujisawa and S. Sato, Denki Kagaku, 23, 238 (1955).

7. T. V. Kramareva and V. M. Shul'mand, Zh. Anal. Khim., 23, 750 (1968); Chem. Abstr., 69: 49087x (1968).

8. J. Prunonosa, R. Obach and J. M. Valles, J. Chromatogr., 377, 253 (1986).

9. M. K. Papay, K. Toth and E. Pungor, Anal. Chim. Acta, 56, 291 (1971).

10. Merck \& Co., Inc., "The Merck Index, 11th Ed., 1989.

11. C. Ribaudo and F. X. Murphy, Report IS; ARLCD-TR80051, AD-E400 534, Order No. AD-A095-378 (1981).

12. M. Sato and H. Sato, Denki Kagaku, 22, 411 (1954).

(Received April 27, 1994)

(Accepted August 16, 1994) 